\title{
Sujeito de Direito e Capitalismo, de Celso Naoto Kashiura Júnior
}

[KASHIURA JÚNIOR, Celso Naoto. Sujeito de direito e capitalismo. São Paulo: Outras Expressões; Dobra Universitário, 2014, 255 p.]

Ricardo Prestes Pazello ${ }^{1}$

A crítica jurídica marxista realiza uma análise do direito tão profunda que seu cerne é quase que totalmente incógnito aos juristas de formação tradicional - e mesmo aos de não tão tradicional formação assim. Não se trata de mera ignorância por falta de acesso às reflexões dos teóricos marxistas a respeito do fenômeno jurídico, ainda que continue havendo limitada disseminação de tais reflexões, em grande parte motivada por um macartismo indômito no cenário acadêmico, jurídico e em geral. Mais do que isso, trata-se de uma incognoscibilidade derivada da naturalizadíssima vinculação entre direito e normas jurídicas. A impossibilidade da tarefa de conhecer o fenômeno para além de o normativismo jurídico por parte dos juristas (estejam eles preocupados com delineamentos conceituais ou com atividades práticas) é proporcional aos avanços que a crítica jurídica marxista faz.

No Brasil, estes avanços vêm ocorrendo e a obra de Celso Naoto Kashiura Júnior é significativo exemplo disso. O livro Sujeito de direito e capitalismo, lançado em 2014 pela coleção "Direitos e lutas sociais" da parceria entre as editoras Outras Expressões (Expressão Popular) e Dobra Universitário, é resultado da tese de doutoramento do autor e vem a público dois anos após sua defesa na Universidade de São Paulo. Nele, Kashiura Júnior enfrenta a problemática do sujeito de direito, nodal para

1 Professor do Curso de Direito da Universidade Federal do Paraná (UFPR). Secretário nacional do Instituto de Pesquisa, Direitos e Movimentos Sociais (IPDMS). 
a compreensão antinormativista do fenômeno jurídico, atravessando três pilares do pensamento filosófico ocidental moderno: Kant, Hegel e Marx.

O ponto de partida de Kashiura Júnior é, não há dúvidas, a crítica marxista. É por isso, aliás, que a obra tem o objeto de estudos que tem: o sujeito de direito. É provável que, se o marco de análises fosse outro, não se desse a tal objeto o mesmo peso e o direito tornaria a aparecer a partir de mediações secundárias, como a norma, a decisão, o ordenamento ou a linguagem. Não por acaso, portanto, o autor se preocupa com a afinidade existente entre sujeito de direito e capitalismo, na medida em que, seguindo a senda inaugurada por Marx, a análise da realidade concreta impõe a percepção de categorias historicamente construídas, sendo o direito uma delas.

Procura Kashiura Júnior continuar avançando no entendimento do fenômeno jurídico, em conformidade com o método inaugurado por Marx. As categorias explicativas da realidade concreta são sempre relações sociais e, dessa maneira, o marxismo descobriu o vínculo inafastável entre a divisão do trabalho e o capital como relação social. Na exposição marxiana, a mercadoria é a particularidade concreta que permite conduzir a dinâmica do valor no modo de produção capitalista. Assim, a forma mercantil é constitutiva da forma-valor. $\mathrm{E}$ o que isso contribui para a reflexão a respeito do direito? Quem respondeu da melhor maneira tal pergunta foi Pachukanis, jurista soviético do primeiro período da revolução de 1917. A forma jurídica está estreitamente ligada à forma-valor e para compreender ambas é preciso desdobrar o método de Marx que o levou da mercadoria até o capital, passando pela relação de troca e o dinheiro.

Dessa maneira, Kashiura Júnior continua os passos de Marx e Pachukanis, agregando ao conhecimento da forma-valor e da forma jurídica uma análise aprofundada a respeito do sujeito de direito, correspondente jurídico da mercadoria que dele necessita, pois não pode trocar-se sozinha no mercado, para lembrar a imagem elaborada pela pena de Marx.

$\mathrm{O}$ autor divide seu livro em três grandes atos, em que aparecem em cena, cada um a sua vez, três clássicos da filosofia alemã, representados a partir de suas abordagens acerca do sujeito de direito. Adota Kashiura 
Júnior, pois bem, uma metodologia do atravessamento, expressiva do que ele mesmo chamou de "filosofia do direito em transição" (p. 12).

Apesar de o sujeito de direito não aparecer como conceito explícito na obra de Kant, este é o protagonista do primeiro ato escrito por Kashiura Júnior justamente porque expressa o erigir da figura do sujeito moderno. A resultante da perspectiva kantiana é uma ênfase no direito a partir dos objetos aos quais o fenômeno jurídico se dedica, fruto de um liberalismo arcaizante que marca a transição de uma filosofia ainda presa a seus referentes feudais mas que não deixa de se encontrar com problemas típicos do capitalismo.

O não amadurecimento do direito subjetivo na filosofia de Kant obrigou Kashiura Júnior a procurar o que de implícito havia nele que permitia contornar a noção de subjetividade jurídica. O caminho seguido conduz o leitor a se deparar com a racionalidade moderna encarnada na vontade do sujeito moralmente autônomo, ou seja, na "universalidade do sujeito moral" (p. 32). O sujeito é pessoa autônoma, o que implica liberdade, mas isto, adverte Kashiura Júnior, não permite projeções mecânicas para o entendimento do sujeito de direito implícito em Kant, por dois motivos: as especificidades do direito, inclusive na obra kantiana, e as contradições com as quais tal pensamento se defronta.

A liberdade que caracteriza os sujeitos limita-se por uma geometria de respeito à liberdade de outrem. Para garantir tal geometria pode-se, nos moldes kantianos, apelar para a coerção externa, sob égides heterrônomas. Daí a especificidade e, ao mesmo tempo, a contradição de Kant: a normatividade que caracteriza o direito se choca com a autonomia que diz respeito aos sujeitos morais.

Da tensão entre sujeito e objeto resulta, em Kant, uma caracterização do direito pelas coisas sobre as quais este se debruça. Em algum sentido, este horizonte jurídico ainda aprisiona a intelecção dos juristas acerca de seu principal problema. Diz Kashiura Júnior: "o sujeito, na visão kantiana, não se torna proprietário porque se exterioriza nas coisas que adquire, porque faz a sua vontade nelas habitar, mas por um vínculo meramente externo, numa relação em que proprietário e propriedade se mantêm como reciprocamente exteriores" (p. 64). A questão da propriedade da terra é central para a filosofia transitória de 
Kant. A ocupação da terra (objetivamente) prevalece sobre relações interpessoais (subjetivas), o que faz com que Kant tenha de combinar as dimensões real e pessoal para tratar da possibilidade de que alguém se torne assujeitado de outro: a esposa, os filhos, os criados. Kashiura Júnior enfatiza a contraditória classificação criada por Kant que, para além de os direitos reais (ius reale) e pessoais (ius personale), fala também em um ius realiter personale. Esta ênfase é o condão da interpretação de tal filósofo, já que aponta para a tentativa de adequar o inadequável, ou seja, de conciliar o sujeito moral geometricamente limitado pela liberdade dos demais com o direito real-pessoal sobre pessoas com condições jurídicas assimétricas.

Se Kant representa a transição da produção senhorial para a livre circulação mercantil, Hegel é o protagonista da apoteose filosófica burguesa. Se até aqui o sujeito de direito aparecia tão-só implicitamente, agora adquire estatuto central.

Como se costuma dizer, a filosofia hegeliana alberga obscurantismos, mas Kashiura Júnior enfrenta bem seu emaranhado conceitual. Percebe seu ponto de partida nas noções de pessoa, vontade livre e, por conseqüência, sujeito de direito. Ora, rompendo com Kant, a filosofia de Hegel parte do sujeito de direito. A virtude da análise de Kashiura Júnior é sempre pontuar a vinculação entre produção filosófica e contexto histórico: Kant, na transição feudal-capitalista, não poderia ser o representante máximo da filosofia do direito como Hegel, justamente porque só este conhece os desdobramentos da nova dinâmica de produzir a vida.

Com Hegel apresenta-se a especificidade do sujeito de direito a partir do capitalismo. Não como dever-ser, mas como resultado da evolução histórica. Da abstração sujeito de direito é que se desdobra a noção de proprietário e não o contrário. Até por isso, não há mais a mediação jurídica fundada na relação pessoa-coisa; antes todos são sujeitos de direito e a partir de suas relações entre si é que se origina a relação com as coisas. Logo, "Hegel sepulta o modelo segundo o qual o objeto dá significado ao direito: todo o direito decorre do sujeito de direito, todo direito é então um direito da personalidade" (p. 112). É assim que além de se desdobrar na noção de propriedade, o sujeito de direito dá vazão para a noção de contrato. 
O realce que Kashiura Júnior dá à influência da teoria do valor-trabalho na obra de Hegel é esclarecedor: "na medida em que concebe a propriedade como exteriorização do sujeito, é capaz de notar que o trabalho não é simples acidente, mas ele mesmo substância" (p. 110). Daí o aparecimento do contrato de trabalho e da relação contratual guiando a sociedade civil, impossibilitando a posse de pessoas sobre pessoas, seja nas relações familiares seja com relação a criados e servos. A sociedade civil, da livre circulação mercantil, é composta por sujeitos de direito: todos atomizados, mas todos sujeitos de direito.

Por fim, quem vem à ribalta é Marx, sem nunca dela ter saído. É a proposta de Marx que promove uma última transição, esta definitiva: a de crítica ao capitalismo. Neste sentido, não é mais o caso de procurar implícita ou explicitamente o sujeito de direito como categoria própria à sociedade que o contorna, mas de estabelecer tal presença como inescapável e criticá-la, já que "a personalidade jurídica está vinculada ao movimento próprio da circulação e da produção de mercadorias, nas formas historicamente determinadas que assumem no modo de produção capitalista" (p. 160).

Como o elo entre mercadoria e sujeito de direito é patente, Kashiura Júnior trata de perceber o significado da "forma subjetiva da relação de troca de mercadorias" (p. 177). Aqui, o autor dá dois importantes passos para a crítica jurídica marxista, já superando os resquícios das influências filosóficas anteriores: o primeiro é o de antecipar e tornar independente o direito da norma que a ele se atribui, ou seja, a relação jurídica (e a constituição de sujeitos de direito) é anterior e independente da norma jurídica; o segundo, e mais interessante ainda, pertine à possibilidade de autonomização da forma jurídica em face de relações não imediatamente mercantis. Este segundo passo instaura uma importante abertura nas leituras do marxismo sobre o direito, concebendo-o para além de uma consolidada ortodoxia privatista (direito apenas como relação contratual privada, ainda que esta seja sua principal manifestação).

Kashiura Júnior também enfrenta uma série de polêmicas internas ao marxismo ou mesmo que são próprias às críticas ao marxismo: vai desde o afastamento de uma concepção de sociedade mercantil simples para expressar a proposta de Marx até a indissociabilidade entre as esferas 
de produção e circulação para caracterizar a forma jurídica, na esteira da apreciação da forma-valor. Todos pontos que merecem atenção das vertentes marxistas e de seus sérios opositores, se não para concordar com eles, ao menos para levá-los em conta quando de novas teorizações.

A forma jurídica tem no sujeito de direito seu segredo e na disposição dos indivíduos como mercadoria, suas bases concretas. A mercantilização do mundo não é apenas a do trabalho passado, mas da própria capacidade de transformar tal mundo. A mercadoria força-de-trabalho é o ápice deste processo, que a cada dia se verticaliza mais. Por isso a necessidade de superar a ideologia jurídica que erige sua própria filosofia como filosofia do sujeito de direito. Romper com ela é uma necessidade para superar as condições às quais estamos submersos. Para fazê-lo é preciso tomar a sério o movimento da práxis de Marx: a ruptura com Hegel implicou assumir uma teoria da revolução proletária, lembra Kashiura Júnior. Se assim é, o direito precisa ser compreendido no contexto que o tornou possível, qual seja, o da equivalência mercantil e jurídica, ao nível da circulação, e o da absoluta e total desigualdade material, ao nível da produção. Se mercadoria, valor, sujeito de direito e forma jurídica têm suas raízes profundas no capitalismo, superar este é superar aqueles, restando não outra conclusão: a "extinção da forma jurídica" como a "pedra fundamental da crítica marxista do direito" (p. 239).

A obra de Celso Naoto Kashiura Júnior é contribuição inquestionável para o atual cenário da crítica jurídica marxista, especialmente no Brasil, onde houve um sensível retrocesso nas teorizações críticas sobre o fenômeno jurídico, marcadas por perspectivas voluntaristas ou de cunho neo/pós/transconstitucionalista. Por outro lado, esta mesma crítica marxista ainda precisa avançar na concretização de seu programa político-intelectual de intervenção na realidade, para manter acesa a contribuição maior de Marx - a práxis. Para esta dupla tarefa - redignificação teórica e programa político - todos os críticos marxistas do direito estão instados. Oxalá o contato com os movimentos populares seja sua via preferencial de acesso ao cumprimente de tal tarefa. 